\title{
How to modify the axis of a self-expandable metal stent to avoid malfunction in gastric outlet obstruction: a simple trick
}

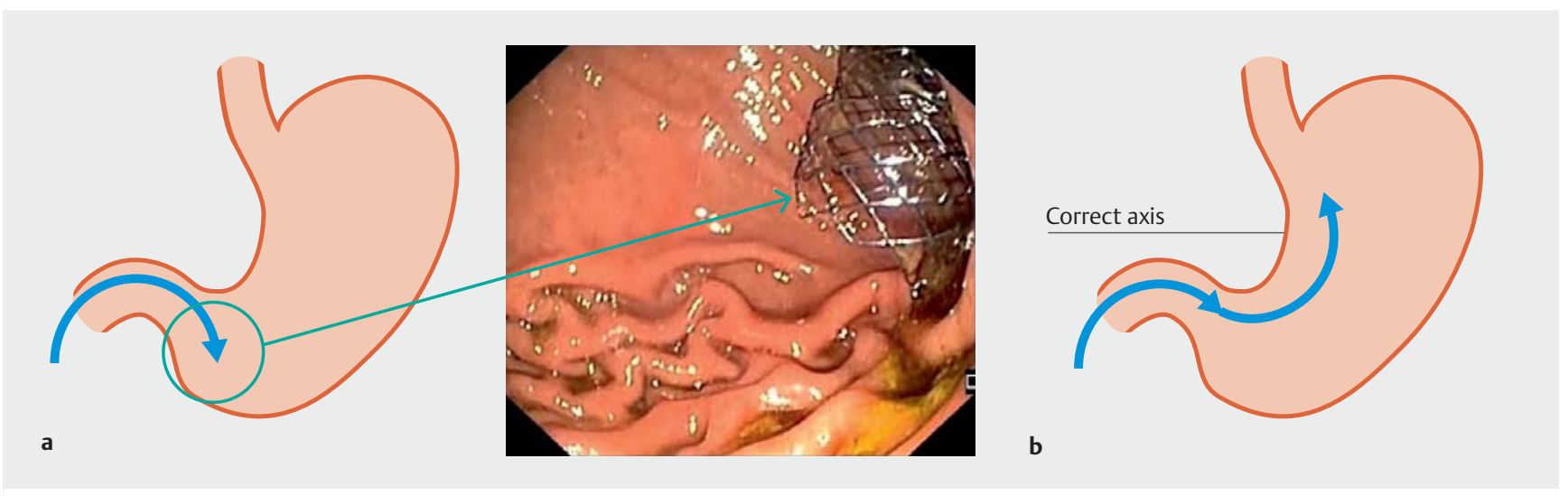

- Fig. 1 Axis of a self-expandable metal stent after its deployment. a Before modification. b After modification by a standard clip.

Malignant gastric outlet obstruction (GOO) is caused mainly by gastric or pancreaticobiliary neoplasms. GOO presents with uncomfortable symptoms, such as nausea, vomiting, and abdominal distension, leading to malnutrition and impaired quality of life [1,2]. Endoscopic placement of a self-expandable metal stent (SEMS) is widely accepted as nonsurgical palliative treatment of nonresectable malignant GOO [3]. However, the efficacy of the SEMS can be compromised, especially in patients affected by gastric antral neoplasia, in which GOO relief is not completely obtained. One of the reasons why gastric SEMS can be ineffective is possibly due to the impact of the proximal end of the stent at the great curvature of the gastric body ( $\triangleright$ Fig. 1 a). Four patients who were unfit for surgery underwent SEMS placement for malignant GOO (three women: 25, 52, and 56 years old; and one 57-year-old man). With a standard clip we caught the proximal end of the stent, closing the clip inside the mesh of the body of the SEMS ( $\triangleright$ Video 1 ). This trick modifies the proximal axis of the stent ( $\vee$ Fig. $\mathbf{1} \mathbf{b}$ ), restoring the normal anatomy of the stomach ( Fig.2).

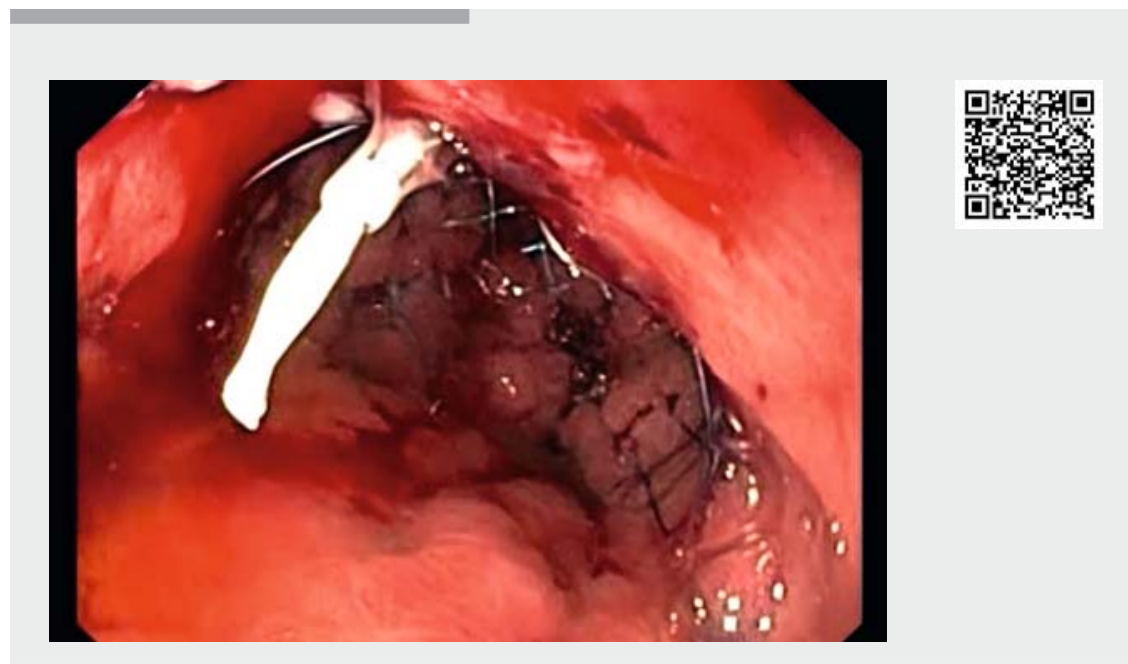

Video 1 Modification of the axis of a self-expandable metal stent to avoid malfunction in gastric outlet obstruction.

This treatment aims to avoid malfunction of the SEMS by using the clip to modify the axis of the stent and restore the normal anatomy of the stomach.

Endoscopy_UCTN_Code_TTT_1AO_2AZ

\section{Competing interests}

The authors declare that they have no conflict of interest.
The authors

Benedetto Mangiavillano ${ }^{1,2}$, Francesco Auriemma ${ }^{1}$, Mario Bianchetti ${ }^{1}$, Alessandro Repici ${ }^{2,3}$

1 Gastrointestinal Endoscopy Unit, Humanitas Mater Domini, Castellanza, Italy

2 Humanitas University, Milan, Italy

3 Digestive Endoscopy Unit, Istituto Clinico Humanitas Research Hospital, Milan, Italy 

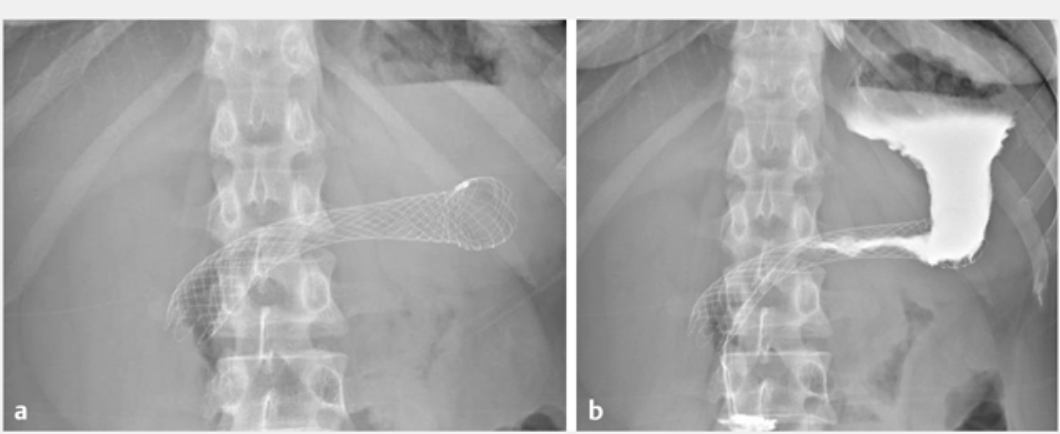

- Fig. 2 X-ray images. a Proximal part of the self-expandable metal stent (SEMS) with the modified axis. b Correct progression of the contrast medium after SEMS modification.

\section{Corresponding author}

\section{Benedetto Mangiavillano, MD}

Gastrointestinal Endoscopy Unit, Humanitas

- Mater Domini, Via Gerenzano n.2,

21053 Castellanza (VA), Italy

Fax: +39-0331-476210

bennymangiavillano@gmail.com

\section{References}

[1] Brimhall B, Adler DG. Enteral stents for malignant gastric outlet obstruction. Gastrointest Endosc Clin N Am 2011; 21: 389-403

[2] Tonozuka R, Itoi T, Sofuni A et al. Endoscopic double stenting for the treatment of malignant biliary and duodenal obstruction due to pancreatic cancer. Dig Endosc 2013; 25 (Suppl. 02): 100-108

[3] Boskoski I, Tringali A, Familiari P et al. Selfexpandable metallic stents for malignant gastric outlet obstruction. Adv Ther 2010; 27: $691-703$

\section{Bibliography}

DOI https://doi.org/10.1055/a-1015-6423

Published online: 8.10.2019

Endoscopy 2019; 51: 232-233

(c) Georg Thieme Verlag KG

Stuttgart · New York

ISSN 0013-726X

\section{ENDOSCOPY E-VIDEOS}

https://eref.thieme.de/e-videos

开四 Endoscopy E-Videos is a free Fris access online section, reporting 回: on interesting cases and new techniques in gastroenterological endoscopy. All papers include a high quality video and all contributions are freely accessible online.

This section has its own submission website at https://mc.manuscriptcentral.com/e-videos 